\title{
Digital Content Learning and Mobile Application Assessment for Rural Area using SIERRA
}

\author{
by : SEAMEO SEAMOLEC
}

Abdul Rizal Adompo

abdulrizal@seamolec.org

http://www.seamolec.org

\begin{abstract}
The potential of Information and Communication Technology (ICT) in education, especially learning system, could be optimized in every level in education. In the era of global interconnectivity between institutions, experts, and various learning resources, interaction can be conducted everywhere at anytime by anyone.

Meanwhile, The integration ICT in education espescialy for Open and Distance Learning is not a simple thing. The opportunities provided by ICT to support teaching and learning require a cost. Even there are a number of difficulties which act as barriers which prevent teachers to integrate ICT into learning activity. The region, no-internet connection, and less electricy in many remote areas are still become a main problem on implementing ICT.

SIERRA or SEAMOLEC Educational Resources for Remote Areas is a product that allow students to learn by accessing learning materials such as video, audio, and 60,000 contents compiled in an offline site.this device also can be uses as assessment or try out replacing Computer Based test (CAT). Students can access SIERRA by using their smartphones or Personal Computer (PC) without using internet connection. SIERRA can be one an effective learning alternative for students and teacher to implement 21st century learning.
\end{abstract}

Keywords : Information and Communication Tecnology, Open and Distance Learning, No-Internet Connection, Remote Areas. 


\section{SEAMOLEC Educational Resources for Remote Areas (SIERRA)}

\section{A. Introduction}

The world of education in Indonesia is facing an interesting challenge to be anticipated. Thousands of islands spread out in its vast area, heterogenous society, and the dynamic economic growth are among the important factors for education practitioners to realize one of the nation's future goals, which is to enrich the life of the nation. As an archipelago country with over that 270 million of population spread out all over 17,000 islands, Indonesia will find it quite challenging to realize the idea of enriching the life of the nation as well as to practice the 21st century learning concept. Obstacles arise from the geographic contours, the unsatisfactory statistical data about technology and internet literacy, to the insufficient ICT facilities provided by the Ministry of Education.

The gross enrollment number of Primary school is quite high, is $98.20 \%$, this achievment was the impact due to the success of 9-year Compulsory Education Program. While gross enrollment number of intermediate level reached $70.53 \%$ and it means there are $28 \%$ of junior high graduates who have failed at the secondary level ${ }^{1}$. This number is representing children who did not receive education in secondary education; this number excluded the accumulation of graduates in previous years and the potential to allow them to continue their education in subsequent years.

The low of gross enrollment number in secondary education, which is only $70.53 \%$, due to the increasing number of school dropouts and graduates who did not proceed their education to the secondary level. The Limitations of the Capacity for secondary education is also brought about the junior high school graduates did not proceed to secondary education. The Indonesian Government through the Ministry of Education and Culture continues to work on improving the gross enrolment number level of secondary education. The increase target children aged $16-18$ years is $4 \%$ per year. Regarding this issue, alternative and effective solution is required.

In line with prior mentioned issue, the government through the universal secondary education program tried to open equality access to secondary level for providing broader opportunities for public to acquire education at the secondary level. In achieving educational equity in the secondary level, the government envision the necessary to implement Open Schools in order to facilitate special education services.

\section{B. ICT in Learning}

The United Nations Educational, Scientific and Cultural Organization (UNESCO) use the term ICTs, or information and communication technologies, to describe: "...the tools and the processes to access, retrieve, store, organize, manipulate, produce, present and exchangeinformation by electronic and other automated means. These include hardware, software and telecommunications inthe forms of personal computers, scanners, digital cameras, phones, faxes, modems, CD and DVD players andrecorders, digitized video,

\footnotetext{
${ }^{1}$ Ministry of Education and Culture, Republic of Indonesia, 2014.
} 
radio and TV programmes, database programmes and multimedia programmes"(Anderson, 2005) ${ }^{2}$

The potential of Information and Communication Technology (ICT) in education, especially learning system, could be optimized in every level in education. In the era of global interconnectivity between institutions, experts, and various learning resources, interaction can be conducted everywhere at anytime by anybody. Mastering the use of information technology, media, and communication or ICT Skills means that students are able to access information effectively and efficiently; to critically evaluate information; and to manage information in order to help solve problems. Students are also expected to be able to analyse information media; and to create appropriate media for communicating. In the future this expertise would be very important for human resources to compete in the work field. There are Six Key Dimensions on Potential of ICT to Revolutionize Learning. ${ }^{3}$

\section{Connectivity - access to information is available on global scale}

As long as people use internet connection, they can go anywhere to seek information which is available in world wide web (www). Seeking information is not too difficult by using the search engine such as Google or other search engine.

\section{Flexibility - learning can take place any time, any place}

With the "old" style of learning, students have to attend the class in order to learn subject matter. Now day, this rule is not fully functioning. People can study from materials in CD, from web-based materials, from audio-visual, or from the teacher in the class. Students can use all of those features to enhance their knowledge. Therefore, some choices in how to learn subject matters are available. Students or people have more flexibility in studying things. They can learn not only in one place (class) in certain time but also at any time and any place where they have access to computer and internet.

\section{Interactivity - assessment of learning can be immediate and autonomous}

By using ICT completed with assessment tests, students/people can do a test any where they want. The results will be shown directly after they finish the test. Students do not need to wait for some weeks to test's result.

4. Collaboration - use of discussion tools can support collaborative learning beyond the classroom

Since distance is not a problem anymore and since by using internet people is in a big network, discussion among people become easy. This feature can be used by students to discuss their ideas, problems or anything else to colleagues, or professor. Team works can also use this fea ture. Sharing idea between group member can also be done in this way.

5. Extended opportunities - e-content can reinforce and extend classroombased learning

Before the wide use of ICT, students usually learn from the teachers in a class room by using standard books. However, the use ICT can shift this paradigm of teaching-learning. Teacher can give instruction from one place and students can read the instruction from

\footnotetext{
2 Anderson, J., (2005)

${ }^{3}$ Herman, Timbul Pardede, 2007
} 
different place. This illustration showed that teaching-learning activity was not in the same place nor in the same room. Teacher and students can be in different area but the teaching- learning process still work.

6. Motivation - multimedia resources can make learning fun.

By using ICT students will have many learning sources. For example in web, people can find many sources from many subjects. Some subjects are not free. Many subjects were also written in CD. Students can also learn from CD. The way subjects were displayed usually interesting. This fact probably can raised students' motivation in studying.

The advancement of ICT can now offer effective and efficient learning supports at all levels of education and in all fields of knowledge, especially in open and distance learning. Multimedia tools can provide stimulating interactive application for learning at home, in school, and in the workplace. Learners can share learning experiences over great distances through the use of collaborative learning tools. While the internet and the World Wide Web play a leading role in this technological breakthrough, other telecommunication technologies like audio and video conference are still also very important in providing quality interactive learning support in many open and distance learning systems. One manifestation of this trend is the application of ICT in appropriate combination with traditional face-to-face classroom based teaching and learning to improve access to quality education, as well as to provide practical support for learning about the digital tools of today's society.

The 21st century individuals also need to be able to apply technology in the field of information and communication. It has been stated in the 21st century learning concept that requires learners to master 3 skills; Life and Career Skills, Learning and Innovation Skills, and Information, Media, and Technology Skills.

\section{Challenge on Integration ICT into Learning in Indonesia}

The integration ICT in education is not a simple thing. The opportunities provided by ICT to support teaching and learning are not problem-free. Even there are a number of difficulties which act as barriers and prevent teachers to integrate ICT into the classroom. The difficulties might be found on insufficient number of computers, lack of free time for learning and lack of classroom time for students to use computers, teachers' insufficient ICT knowledge and skills, and insufficient technical supports at schools and little access internet.

In 2014, Ministry of Education and Culture (MoEC) through Southeast Asia Ministers of Education Organization Regional Open Learning Center (SEAMOLEC) undertook a program to open access for students who cannot proceed to the next education level, this program namely Open High School. The Open High School Program is an alternative delivery mode for secondary education designed for students who cannot attend the regular high school program due to problems with distance, financial difficulties, and social constraints. This program refers to ministerial regulation 119 year 2014. 
Completing Regulation no. 72, MoEC issued Regulation no. 119 year 2014, which provides guidance on how to run Open Distance Learning (ODL) in primary and secondary education. This regulation mentioned $\mathrm{in}^{4}$ :

Chapter I about General Requirement in Article 1 stated that Distance Education, hereinafter referred ODL is education participants who separate from educators and participants using a variety of learning resources through the application of the principles of education technology / learning.

While in Chapter II about Objectives, Characterisitic, and Scope, the regulation in Article 3 stated that ODL has the characteristics of an open, self-learning, mastery learning, using information and communication technology education, and / or more use of educational technology.

For secondary education, Indonesia has launched Open High School Program (SMA Terbuka) in 2015. There were 6 schools in 6 provinces in Indonesia involved as pilot project, the addressed provinces as follows; West Java, East Java, West Papua, West Nusa Tenggara, Jambi, and South Kalimantan. The similarity of geographical characteristic issue due the location on remote area, as well as the unequipped with supportive educational infrastructure. Distance Learning in Secondary Education in Indonesia conducted in 3 modes on learning material delivery, as follows:

1. $75 \%$ in face-to-face and $25 \%$ ODL.

2. $50 \%$ in face-to-face and $50 \%$ ODL.

3. $25 \%$ in face-to-face and $75 \%$ ODL.

The learning activity for this program conducted as follows:

1. Delivery system was using Edmodo application as online learning media.

2. Students provided by tablet device and monthly internet access subscription.

3. Regular face-to-face tutorial in Learning Centre conducted twice a week.

4. Tutors are facilitating student in order to discuss any arisen problem during independent learning session, as well as to facilitate students during practicum session based on tutor speciality in courses.

5. Teachers visit Learning Centre once a month to monitor student' learning progress.

The tablet devices were available for students and completely equipped with learning material and applications, as well as Learning Management System (LMS) as virtual class. The LMS able to be accessed by school through $75 \%$ online access. Frequently asked questions accommodated by teacher assistants located nearby the students. For school which applying $75 \%$ face-to-face method, digital book provided for students as one of the implementation ICT integration in learning.

Several findings from model implementation, as follows:

1. The learning materials provided in video format, consequently it requires big internet connection to access and download the material.

2. The expenditure regarding the internet access subscription became troublesome to the students, as well as for parents incapable to provide additional internet access subscription.

\footnotetext{
${ }^{4}$ Ministry of Education and Culture, Republic of Indonesia, 2014.
} 
3. The insufficient mobile signal for internet connection.

4. The insufficient electricity supply.

5. The damage of computer equipment due to the insufficient electricity supply.

Against the findings, the key question when considering the potential of ICT in secondary education is how ICT able to exploit as a catalyst to transform education systems. Thus, ICT projects often serve to further alienate and marginalize those at the bottom of the system, while they increase inefficiencies by creating new costs without increasing productivity across the system in any noticeable ways.

\section{SIERRA Inovation}

A good nation certainly will not back down when facing obstacles. On the contrary, from this point, innovation and creative ideas will arise. A one of innovation for education namely SIERRA has been launched. SIERRA or SEAMOLEC Educational Resources for Remote Areas is a product that allow students to learn by accessing learning materials in form of video, audio, and 60,000 contents compiled in an offline site, by using their smartphones or Personal Computer (PC) without using internet connection. Another function of SIERRA can be use also by student to practice tryout or do assessment replacing Computer Based Test(CAT). Teacher just make the assessment question for example multiple choices through the assessment application that embedded on SIERRA, and then the student can access it. Teacher even can download the result via spreadsheet and make analytic student progress according to the result.

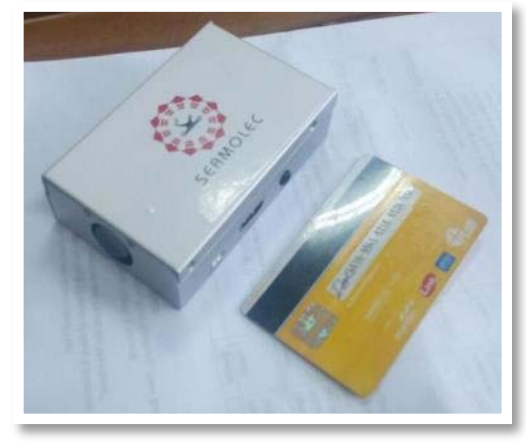

Picture 1. SIERRA Device

Available contents in SIERRA among others are results from cooperation with Rumah Belajar (PUSTEKKOM), Khan Academy, Biovision, Mathematics Lab, and many more, which can be adapted. SIERRA can be inserted with learning materials as needed by schools, teachers, or the institution as user. This will certainly provides distinct advantages from schools/relevant educational institution, as it can indirectly protect students from accessing dangerous sites or pornography contents. 


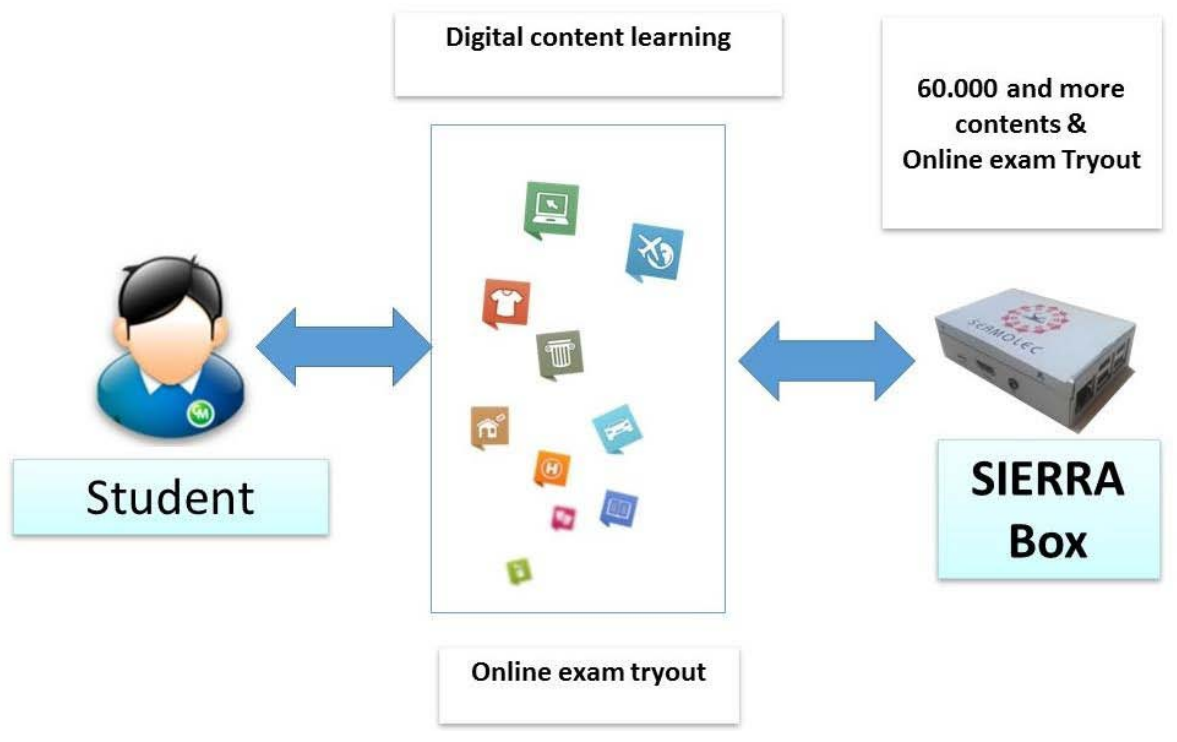

Picture 2. SIERRA Model

SIERRA comes in as a simple, handy, and easy to carry gadget with the size no larger than a credit card. Not only to assist students in self-learning process, SIERRA allows students to follow online test exercise or computer-based test only with the use of their smartphones. Schools will no longer need to provide PC or computer lab and internet connection. One unit of SIERRA can provide 60,000 offline contents or more that 1000 quizzes for try out test. All can be directly accessed from their gadgets without internet connection and it also saves electricity.

From research conducted by ICT team in SEAMOLEC, there are several options regarding devices development that can substitute the role of computer laboratory facilities. Furthermore, how to achieve affordable internet connection service, among others the use of mini microcontroller board, SD card, access points that configured to be a mini-PC / Server that to able to injected by software of content of education.

The basic components used by SEAMOLEC research team in developing SIERRA device to support education, as follows:

\begin{tabular}{|l|l|}
\hline CPU & $\begin{array}{l}\text { A83T ARM Cortex-A7 octa-core,512 KB L1 cache 1 MB L2 } \\
\text { cache }\end{array}$ \\
\hline GPU & $\begin{array}{l}\text { PowerVR SGX544MP1. Comply with OpenGL ES 2.0, OpenCL } \\
\text { 1.x, DX } \\
9 \_3\end{array}$ \\
\hline Memory & 2GB LPDDR3 (shared with GPU) \\
\hline Storage Support & $\begin{array}{l}\text { MicroSD Card(up to 64GB)/SATA(up to 2TB USB-to-SATA; } \\
\text { GL830)/eMMC(8GB onboard) }\end{array}$ \\
\hline $\begin{array}{l}\text { Onboard } \\
\text { Network }\end{array}$ & 10/100/1000Mbps ethernet (Realtek RTL8211E/D) \\
\hline WiFi & 802.11 b/g/n (AP6212) \\
\hline Bluetooth & BT4.0 (AP6212) \\
\hline Video In & $\begin{array}{l}\text { Parallel 8-bit camera interface MIPI Camera serial } \\
\text { Interface(CSI) }\end{array}$ \\
\hline
\end{tabular}




\begin{tabular}{|l|l|} 
Video Out & $\begin{array}{l}\text { HDMI 1.4 DHCP 1.2 with resolutions from(640x640 to } \\
\text { 1920x1080) } \\
\text { MIPI DSI for RAW LCD panels }\end{array}$ \\
\hline Audio Out & 3.5 mm Jack and HDMI \\
\hline Audio In & On board microphone \\
\hline Power Source & Micro USB, optional 5V DC port (center positive 1,6 x 4,4mm) \\
\hline USB Ports & 2x USB 2.0, USB OTG(Micro USB) \\
\hline Buttons & Reset button, Power button, U-boot button \\
\hline GPIO & $\begin{array}{l}\text { 40 Pins: GPIO, UART, I2C bus, I2S bus, SPI bus, PWN, +3.3v, } \\
+5 \mathrm{v}, \\
\text { ground }\end{array}$ \\
\hline LED & Power LED(red), RJ45 LED(blue), user define LED(green) \\
\hline OS & Android and Linux etc.OS \\
\hline Dimensions & $92 \mathrm{~mm} \times 60 \mathrm{~mm}$ \\
\hline Weight & $45 \mathrm{~g}$ \\
\hline
\end{tabular}

Table 1 : Sierra Specification

The SIERRA intensively developed since 2016 with aimed in providing educational content at affordable prices, and provide performance as standard personal computer. The device is able to be customized into education support device. The learning contents can be accessed with less electricity and no internet connection. The main idea was digital contents required to be accessed by students through Internet, CAT applications, and other interactive digital learning media now can be accessed using this SIERRA.

In comparation with regular standard computer lab to be used for teaching and learning activity in 21st century, the cost of developing SIERRA device is relatively more affordable, as shown in the comparation table below.

\begin{tabular}{|l|l|l|l|}
\hline Small Computer Lab & Cost & SIERRA & Capacity \\
\hline 40 Personal Computer & @ 500 USD x40 & $\begin{array}{l}\text { Smartphone/ tablet } \\
\text { @100 USD x40 }\end{array}$ & 40 studens \\
\hline Networking Cable & 150 USD & $\begin{array}{l}1 \text { Power Bank : } \\
100 \text { USD }\end{array}$ & \\
\hline Switch 2 pcs & 400 USD & - & 10 Mbps \\
\hline Cost for Internet Connection & 600 USD / years & - & \\
\hline & & & \\
\hline Total Cost* & 21.150 USD & 4200 USD & \\
\hline
\end{tabular}

Table 2 : comparation estimate cost beetween Lab computer and SIERRA Device

note: * the price shown in the table above is only estimated price in 2016

\section{E. Implementation of SIERRA}

During year 2017 - 2018 SIERRA has been implemented in several locations in Indonesia and abroad. In order to support the efforts to strengthen community capacity for disaster risk reduction in the CaRED (Community Resilience and Economic Development) program, SIERRA utilization implemented in Ternate - North Maluku, as well as to improve access and quality of Learning in West Papua, Aceh Jaya - Aceh, as well as Kinabalu and Sabah in Malaysia. 
The table below provides information regarding the number of beneficiaries during the implementation of SIERRA. The beneficiaries are individuals who received a service in the past a year. The beneficiaries including students and teachers in primary and secondary school.

\begin{tabular}{|r|r|r|r|}
\hline Gender & Students & Teachers & \multicolumn{1}{c|}{ Total } \\
\hline Female & 2291 & 160 & 2451 \\
\hline Male & 2350 & 160 & 2510 \\
\hline Total & 4641 & 320 & 4961 \\
\hline \multicolumn{2}{r|}{ Table 3 : Number of Beneficiaries in Utilization of SIERRA }
\end{tabular}

The information below provides information regarding the implementation of the utilization of SIERA in several locations.

\section{SMA Terbuka Padalarang (Padalarang Open High School)}

SIERRA has been applied in SMAN 2 Padalarang which act as reference school in Open High School (SMA Terbuka) Padalarang. This device is chosen as solution to access learning materials without internet, for this school is lacking of internet connectivity. Through SIERRA, teachers could develop digital contents to be stored in the local server of SIERRA when they are connected with internet, which later can be saved in the server of learning venue or Tempat Kegiatan Belajar (TKB). Then these contents are ready to be accessed by students. SIERRA installation in Padalarang is highly recommended based on its highlands topography. During SIERRA trials, recorded a number of 126 students were in Cihampelas Learning Activity Unit.

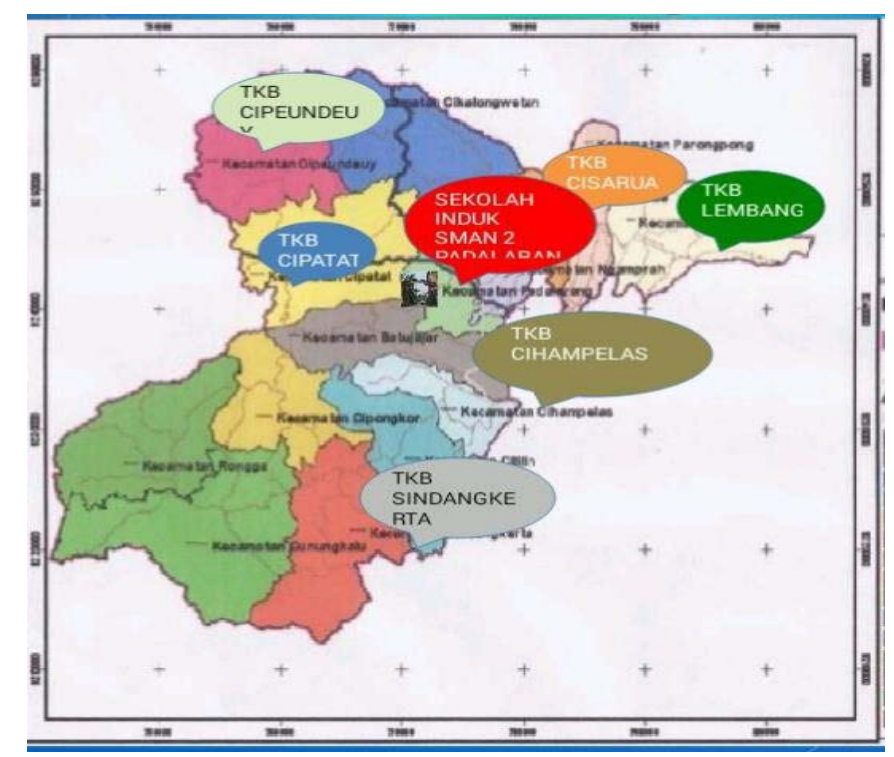

Picture 3. Map of West Bandung Regency

West Bandung Regency of West Java Province is one of the assigned areas to apply open school model, the assigned school is SMAN 2 Padalarang (Padalarang Public High School No.2) as the ODL Provider and involving several areas as Learning Centre location, including; Lembang District, Cisarua District, Cipeundeuy District, Cipatat District, 
Cihampelas District and Sindangkerta District. With the number of students 400 students, open school provided students with digital learning recources able to be accessed using SIERRA.

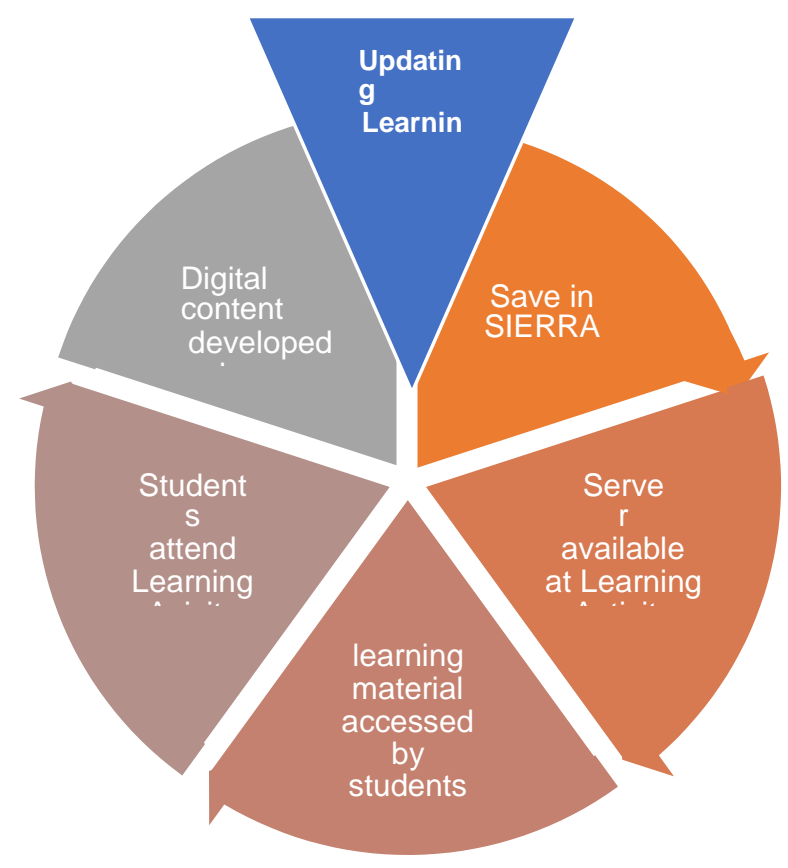

Picture 4. Model of Open School using SIERRA

The implementation of distance learning model applying SIERRA in SMAN 2 Padalarang and 6 Learning Centre conducted in 2 activities. The first activity was system trial and the second activity was launching and inauguration of open school program. The trial activity covered; socialization to local officials, principals and teachers; presentation material to the stakeholders, and hands on experience for teachers, tutors, and students.

The piloting activity conducted in classrooms, participated by 120 students, and divided into three classrooms, due the limited capacity of the classrooms. The activity begun with introduction to the SIERRA and online test activity then proceed with the utilization of SIERRA to access learning materials. Students were directed to access the learning material then assisted to install online test applications which also provided by SIERRA.

After the students had completed installing and registering online test system, furthermore students were required to complete the test. The test provided by teachers SMAN 2 Padalarang, and dedicated to tryout this system. Feedback from students in the implementation was image display, students were hoping the image display could be enlarged and more clear.

2. Sekolah Indonesia Kota Kinabalu (School of Indonesia in Kota Kinabalu Malaysia) School of Indonesia in Kota Kinabalu (SIKK) established as government' attention towards Indonesian children education in Sabah Malaysia. The establishment based on Minister of National Education Decree year 2008, SIKK established in order to provide education access 
for Indonesian children in Sabah for formal and non-formal education. The vast region, spread out and secluded locations have made learning delivery in distance become crucial. In order to support and facilitate SIKK in ODL programs for primary and secondary education, SEAMOLEC provided assistance in implementation the utilization SIERRA as alternative technology in providing digital learning material access towards students, as well as to encourage teachers in developing learning materials especially in web-based learning material.

The picture below provides information regarding the SIERRA location outspread in Malaysia.

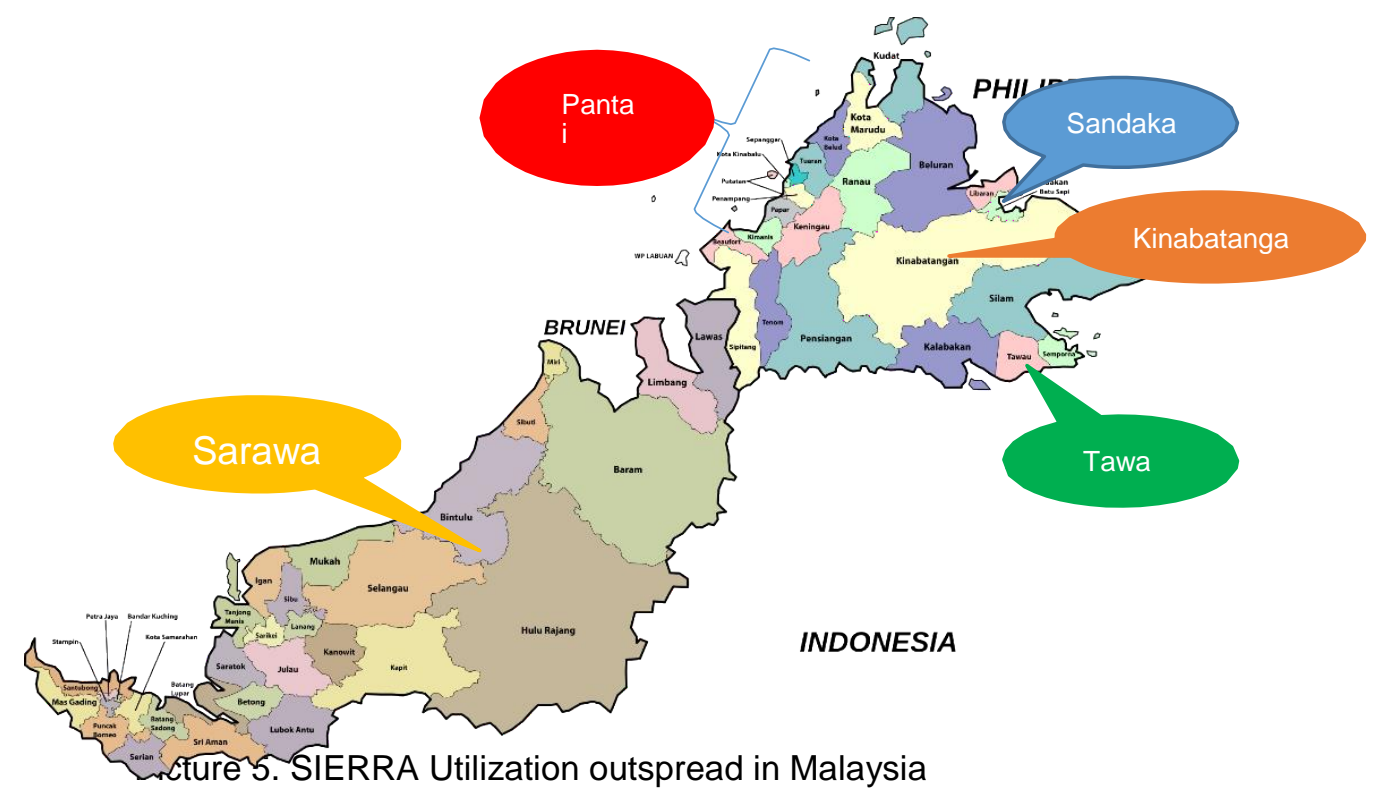

The table below provides information about number of SIERRA in each location outspread in Malaysia.

\begin{tabular}{|c|l|c|}
\hline No & \multicolumn{1}{|c|}{$\begin{array}{c}\text { Locatio } \\
\mathbf{n}\end{array}$} & $\begin{array}{c}\text { Number of } \\
\text { SIERRA }\end{array}$ \\
\hline 1. & Pantai Barat & 5 \\
\hline 2. & Sarawak & 6 \\
\hline 3. & Sandakan & 6 \\
\hline 4. & Kinabatangan & 5 \\
\hline 5. & Tawau & 8 \\
\hline
\end{tabular}

\section{F. Conclusion}

Nowadays, distance education utilizes modern computing and telecommunications technologies, which generally referred to as Information Communication Technology (ICT). Distance education is an educational activity, and therefore the core teaching functions of presenting the learning content, providing for assessment, planning for dialogue that we see in the classroom situation should also be present in the distance teaching situation. Dedicated ICT-related interventions in education that introduce a new tool for teaching and learning may show improvements. 
In conclusion, with all the innovation in technology, the idea of integrating ICT into teaching and learning in remote areas is no longer impossible. With SIERRA, the problem of funding and cost to provide technology for the students can be reduced effectively.

\section{G. Reference}

1. Anderson, J., (2005), "IT, E-learning and teacher development," International Education Journal, ERC2004. Special Issue, 2005, Vol. 5(5):1-14.

2. Herman, Timbul Pardede, 2007. ICT for Instruction Advanced Level. Indonesia: SEAMOLEC.

3. Ministry regulation number 119 year 2014.

4. Guidelines for Open Schools in secondary education, Ministry of Education and Culture, Republic of Indonesia, 2014. 